\title{
Serous cystadenoma of the pancreas presenting as a third primary neoplasm
}

\author{
Aydın Şeref Köksal MD¹, Aysel Ülker MD¹, Mehmet Asıl MD¹, Bilge Tunç MD¹, Kemal Arda MD², \\ Metin Şavkılıoğlu $M D^{3}$, Yusuf Özoğul MD ${ }^{3}$, Nesrin Turhan $M D^{4}$
}

\begin{abstract}
AŞ Köksal, A Ülker, M Asıl, et al. Serous cystadenoma of the pancreas presenting as a third primary neoplasm. Can J Gastroenterol 2003;17(9):552-554.

Serous cystadenomas are the most common cystic neoplasms of the pancreas. They may occur solely or coexist with other neoplasms. A $10 \mathrm{~cm}$ mass involving the body of the pancreas was observed in the computed tomography of a 61-year-old man with a previous history of bladder and prostate carcinoma. Ultrasonography and computed tomography of the mass demonstrated multiple small cysts associated with a central calcified scar. A distal pancreatectomy was performed. Pathological examination confirmed the diagnosis of serous microcystic adenoma.

This is the first report of a serous cystadenoma of the pancreas with two metachronous neoplasms. This feature should be kept in mind during the diagnosis and evaluation of patients with serous cystadenoma.
\end{abstract}

Key Words: Bladder carcinoma; Metachronous neoplasm; Pancreas, Prostate carcinoma; Serous cystadenoma

Cystic neoplasms of the pancreas are uncommon and Caccount for approximately $1 \%$ of all pancreatic exocrine neoplasms (1). Despite their rarity, these neoplasms constitute one of the few curable neoplasms of the pancreas.

Serous cystadenoma (SCA) are the most common histological type, accounting for about $25 \%$ of all cystic pancreatic neoplasms (2). They may occur solely or may coexist with other pancreatic tumours such as ductal adenocarcinomas or endocrine tumours (3). Also, some patients with SCA may have previous or concurrent extrapancreatic neoplasms $(2,4-6)$.

The authors present the first report of a SCA of the pancreas with two extrapancreatic metachronous neoplasms. This case demonstrates the possibility of an association with other neoplasms that may contribute to diagnosis and management of SCA patients.

\section{CASE PRESENTATION}

In 1996, a 61-year-old man was admitted to a urology clinic with the chief complaints of dysuria and hematuria. An abdominopelvic ultrasonography revealed small nodules ( $1 \mathrm{~mm}$ to $2 \mathrm{~mm}$ in diameter) located in the bladder. Cystoscopic transurethral resection was performed and transitional cell bladder carcinoma was diagnosed pathologically (grade 1). In 1998, he was readmitted to the same clinic with symptoms of prostatism. Suprapubic pelvic ultrasonography
Cystadénome séreux du pancréas se présentant comme un troisième néoplasme primaire

\begin{abstract}
Les cystadénomes séreux sont les néoplasmes cystiques du pancréas les plus courants. Ils peuvent se produire seuls ou coexister avec d'autres néoplasmes. Une masse de $10 \mathrm{~cm}$ au niveau du pancréas a été observée lors d'une tomographie par ordinateur chez un homme de 61 ans ayant des antécédents de carcinome de la vessie et de la prostate. Une échographie et une tomographie par ordinateur de la masse ont révélé de multiples petits kystes associés à une cicatrice calcifiée centrale. Une pancréatectomie distale a été effectuée. Un examen pathologique a confirmé le diagnostic d'un adénome microcystique séreux. Il s'agit du premier rapport de cystadénome séreux du pancréas avec deux néoplasmes asynchrones. On devrait tenir compte de cette caractéristique lors du diagnostic et de l'évaluation de patients ayant un cystadénome séreux.
\end{abstract}

revealed a hypoechoic mass in the prostate. A pathological examination of the ultrasonography-guided prostate biopsy material confirmed the diagnosis of prostate intraepithelial neoplasm (grade 3). A radical prostatectomy was performed. The patient remained asymptomatic until April 2001, when hematuria and pollakiuria developed. A transrectal ultrasonography-guided prostate biopsy and cystoscopy were performed. Local recurrences of prostate and bladder carcinoma were diagnosed pathologically. Bilateral orchiectomy and transurethral resection were performed, followed by $6600 \mathrm{cGy}$ radiotherapy directed at the pelvis. The patient was placed on bicalutamide (150 mg/day by mouth) treatment. During follow-up in February 2002, a $10 \mathrm{~cm}$ cystic mass involving the body of the pancreas was observed in computed tomography (CT) scanning. There were no prior abdominal ultrasonography or CT demonstrating the pancreas. He was referred to our department for further investigation and treatment.

The patient was asymptomatic. He had no abdominal pain, jaundice or weight loss. There was no history of gallstones, pancreatitis, abdominal trauma or family history of pancreatic disease. He denied using alcohol. He was not a smoker. On physical examination, the liver was palpable $4 \mathrm{~cm}$ below the costal margin. There were no other masses, lymphadenopathy or muscle wasting. Complete blood count and biochemical parameters including the serum transaminases, bilirubin, albu-

Yüksek İhtisas Hospital, ${ }^{1}$ Departments of Gastroenterology; ${ }^{2}$ Radiology; ${ }^{3}$ Gastroenterology Surgery; and ${ }^{4}$ Pathology, Ankara, Turkey.

Correspondence: Dr Aydm Şeref Köksal, Feneryolu sokak 5/21 Etlik, 06010 Ankara, Turkey. Telephone +90-312-3212904,

e-mail dckoksal@hotmail.com

Received for publication February 10, 2003. Accepted July 7, 2003 

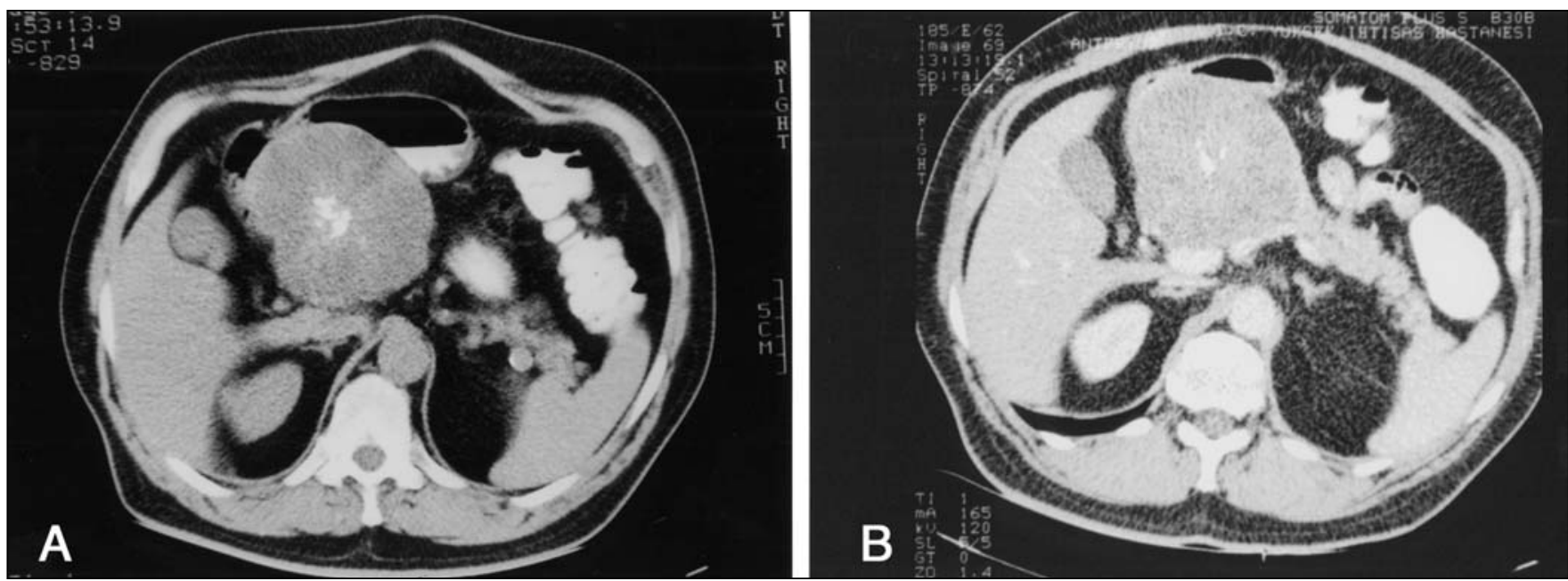

Figure 1) A and B: Computed tomography of the mass with multiple tiny cysts smaller than $2 \mathrm{~cm}$ and a central calcified scar

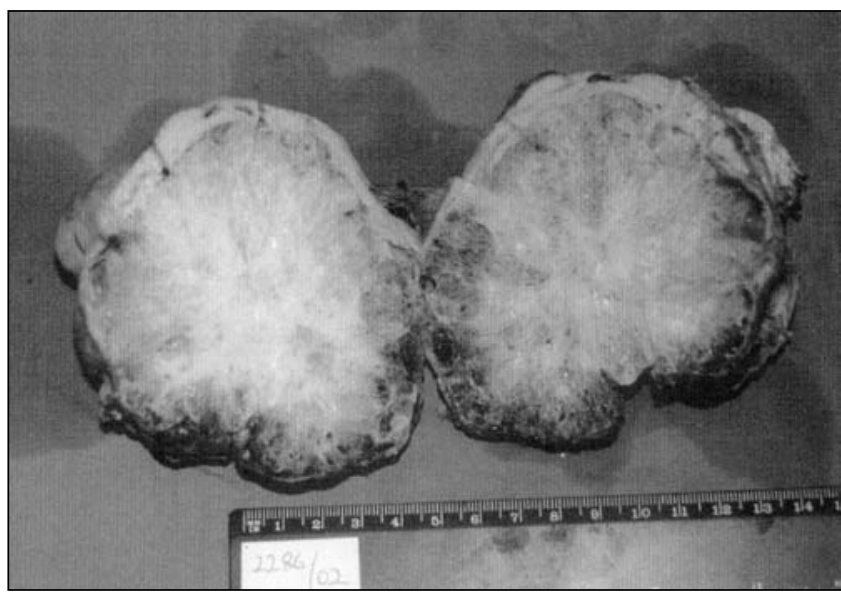

Figure 2) The cut surface of the gross specimen shows a central calcified scar and multiple tiny cysts, giving the tumour a honeycomb appearance

min, alkaline phosphatase, gamma glutamyl transpeptidase, glucose, amilase, creatinine, cholesterol and triglyceride were all within normal limits. Erythrocyte sedimentation rate was $42 \mathrm{~mm} / \mathrm{h}$. Serum CA 19-9 and prostate specific antigen levels were normal. Abdominal ultrasonography showed a $10 \times 10.5 \times 10 \mathrm{~cm}$ mass in the body of the pancreas composed of multiple tiny cysts and a central calcified scar. The splenic artery, superior mesenteric artery and superior mesenteric vein were displaced due to the compressive effect of the mass. They were all patent in doppler ultrasonography. In dynamic contrast-enhanced CT, the density of the mass was 20 to 25 $\mathrm{HU}$ and it had a lobulated contour with multiple tiny cysts smaller than $2 \mathrm{~cm}$ and a central calcified scar (Figure 1). The width of the pancreatic duct was $3 \mathrm{~mm}$. Celiac angiography revealed a hypervascular mass in the body of the pancreas. Based on these findings, a diagnosis of serous microcystic adenoma was suggested. A distal pancreatectomy involving the spleen was performed. The cut surface of the gross specimen showed a well circumscribed, $10 \times 10 \times 8 \mathrm{~cm}$ mass with a central calcified scar and multiple tiny cysts which give the tumour a honeycomb appearance (Figure 2). Microscopic examination with hemotoxylin-eosin staining revealed multiple small cysts containing proteinaceous material lined by a single layer of flat

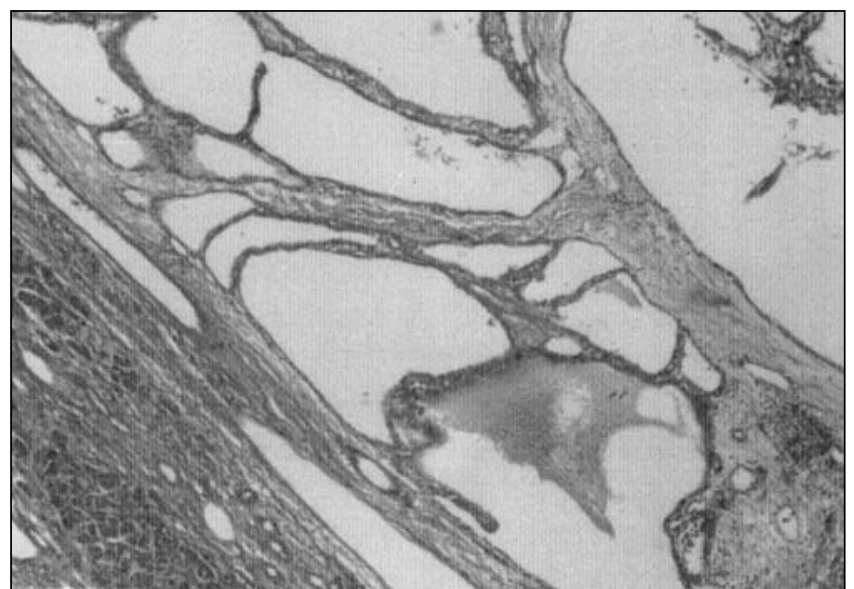

Figure 3) Hemotoxylin-eosin staining of the specimen shows multiple small cysts lined by a single layer of flat or cuboidal epithelium

or cuboidal epithelium (Figure 3). There was not a focus of cancer within the pathological sample. Periodic acid-Schiff stain with diastase digestion demonstrated the glycogen-rich nature of the cell cytoplasm. Cytological analysis with K-ras or other tumour markers could not be done. These findings confirmed the diagnosis of serous microcystic adenoma of the pancreas. Six months after the surgery, an external pancreatic fistula developed. The flow of the fistula was $50 \mathrm{~mL}$ to $60 \mathrm{~mL}$ at the beginning and gradually decreased to $5 \mathrm{~mL}$ to $10 \mathrm{~mL}$. The patient is currently asymptomatic and fistulojejunostomy is planned if the flow of the external fistula does not cease.

\section{DISCUSSION}

Cystic neoplasms of the pancreas are more frequently identified with the advent of improvements in imaging modalities. They account for approximately $10 \%$ to $15 \%$ of cystic lesions of the pancreas and $1 \%$ of pancreatic exocrine neoplasms. Despite their rarity, the distinction between neoplastic and non-neoplastic cysts and between different types of cystic neoplasms is of great clinical importance because their management is different. Therefore, a heightened awareness of the clinical characteristics is necessary for the prompt diagnosis and treatment of the patients. 
SCA are the most common type of histological tumour, accounting for about $25 \%$ of all cystic neoplasms. They are almost always benign neoplasms and occur more than twice as often in women as in men (7). The majority of the patients manifest nonspecific symptoms such as abdominal pain, weight loss, nausea, vomiting, fever and melena. One third of the cases are asymptomatic (3). Our patient had some features such as male sex and asymptomatic presentation, which are not common in SCA.

SCA are often diagnosed as incidental findings during abdominal imaging done for unrelated causes. Because the SCA are composed of multiple cysts less than $2 \mathrm{~cm}$ in diameter separated by thin septa, they may display a honeycomb appearance on CT imaging (8). Radial calcification with a centrally localized scar is pathognomonic and observed in 10\% to $30 \%$ of cases. Enhanced CT and angiography shows hypervascularization, especially in the areas of septation (9). Complete surgical resection of SCAs is curative. Tumours in the body or tail of the pancreas require distal pancreatectomy. Whipple's resection remains the surgical procedure of choice for patients with tumours in the head or uncinate process of the pancreas (4). SCA almost invariably have a benign course. Therefore, SCAs may be conservatively managed and closely followed up in asymptomatic patients, elderly patients or those who have poor operative risks $(2,7)$. Conservative management has the risk of progressive growth of the tumour and development of complications such as hemorrhage, erosion into adjacent structures and gastrointestinal obstruction $(3,6,7)$. Moreover, it has the risk of mistaking a mucinous tumour for SCA.

Several authors have described the association between cystic tumours of the pancreas and other neoplasms. Warshaw et al (2) described the association of a concurrent or previous malignancy with a cystic neoplasm of the pancreas in 13 of 67 patients $(19.4 \%)$. Cancer was located in the pancreas in two patients, in the bile duct in one patient, urogenital tract in six patients and other locations in four patients. Pyke et al (4) described the association of SCA with pheochromocytoma in two patients, insulinoma in one patient, ampullary cancer in one patient, colonic adenocarcinoma in one patient, hairy cell leukemia in one patient, Non-Hodgkin's lymphoma in one patient, cancer of the pharynx in one patient, adenocarcinoma of the cervix in one patient and papillary cancer of the thyroid in one patient. Tarpila et al (5) reported the association of extrapancreatic neoplasms in up to $22 \%$ of their SCA patients. Borgne et al (6) reported a previous $(11.7 \%)$ or concurrent (4.7\%) extrapancreatic neoplasm and another associated pancreatic neoplasm (4\%) in SCA patients. The reason for this frequent association of extrapancreatic neoplasms and SCA is unclear. Several factors such as shared risk factors for the development of pancreatic and extrapancreatic neoplasms, a shared genetic predisposition with the primary neoplasm, altered immunity because of the primary neoplasms and the effect of treatment with radiotherapy and chemotherapy are suggested (10). Another reason for finding this association may be coincidence, since in the course of working up another malignancy, imaging tests are done that may incidentally identify an asymptomatic lesion. There is little information about the molecular biology of the SCA. They lack p53 and K-ras mutations but overexpress $\beta 1$-latency-associated protein, which is a common feature shared with mucin-producing tumours $(11,12)$. Further studies on the molecular biology of SCAs may clarify the association of extrapancreatic neoplasms and SCA.

In this case we present a SCA of the pancreas associated with a bladder carcinoma six years before diagnosis and a prostate carcinoma four years before diagnosis. Neugut et al (13) reported that the relative risk for developing a pancreatic neoplasm as a second malignancy is significantly elevated after bladder cancer in women and prostate cancer in men. But Kleinerman et al (14) reported no excess of pancreas cancer after prostate and bladder cancer. Therefore, the significance of the association between pancreas, prostate and bladder cancer is uncertain. The coexistence of these tumours may be coincidence or may be due to common association with cigarette smoking, although the patient in our case was a nonsmoker.

\section{CONCLUSIONS}

Although it may not reflect a pathogenetic association, SCA may be associated with extrapancreatic neoplasms. This feature should be kept in mind during both the diagnosis and evaluation of SCA patients. A complete medical investigation is necessary which may increase the chance of detecting concurrent neoplasms at a curable stage. On the other hand, SCA should be considered in the differential diagnosis of pancreatic masses in patients with coexisting extrapancreatic neoplasms.

\section{REFERENCES}

1. Cubilla AL, Fitzgerald PJ. Classification of pancreatic cancer (nonendocrine). Mayo Clin Proc 1979;54:449-58.

2. Warshaw AL, Compton CC, Lewandrowski K, Cardenosa G, Mueller PR. Cystic tumors of the pancreas. New clinical, radiologic and pathologic observations in 67 patients. Ann Surg 1990;212:432-45.

3. Compton CC. Serous cystic tumors of the pancreas. Semin Diag Pathol 2000;17:43-55.

4. Pyke CM, Heerden JA, Colby TV, Sarr MG, Weaver AL. The spectrum of serous cystadenoma of the pancreas. Ann Surg 1992;215:132-9.

5. Tarpila E, Borch K, Franzen L. Cystic neoplasms of the pancreas: A clinicopathologic study of 38 cases. Dig Surg 1989;6:138-41.

6. Borgne JL, Calan L, Partensky C. Cystadenomas and cystadenocarcinomas of the pancreas. Ann Surg 1999;230:152-61.

7. Compagno J, Oertel JE. Microcystic adenomas of the pancreas (glycogen-rich cystadenomas). Am J Clin Pathol 1978;6:289-98.

8. Healy JC, Davies SE, Reznek RH. CT of microcystic (serous) pancreatic adenoma. J Comput Assist Tomogr 1994;18:146-8.

9. Itai $Y$, Ohhashi K, Furui S, et al. Microcystic adenoma of the pancreas: Spectrum of computed tomographic findings. J Comput Assist Tomogr 1988;12:797-803.

10. Tucker MA, Caggana M, Kelsey K. Secondary cancers. In: Cancer Medicine. Holland JF, Frei E III, Bast RC Jr, eds. Philadelphia: Lea and Febiger, 1993:322-39.

11. Ishikawa T, Nakao A, Nomoto S, Hosono J, Harada A, Nonami T. Immunohistochemical and molecular biologic studies of serous cystadenoma of the pancreas. Pancreas 1998;16:40-4.

12. Van Laethem J-L, Resibois A, Rickaert F, et al. Different expression of transforming growth factor $\beta 1$ in pancreatic ductal adenocarcinoma and cystic neoplasms. Pancreas 1997;15:41-7.

13. Neugut AI, Ahsan H, Robinson E. Pancreas cancer as a second primary malignancy. Cancer 1995;76:589-92.

14. Kleinerman RA, Lieberman JV, Li FP. Second cancer following cancer of the male genital system in Connecticut, 1935-82. Natl Cancer Inst Monogr 1985;68:139-47. 


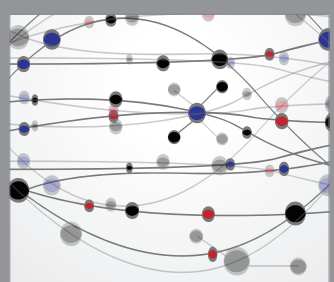

The Scientific World Journal
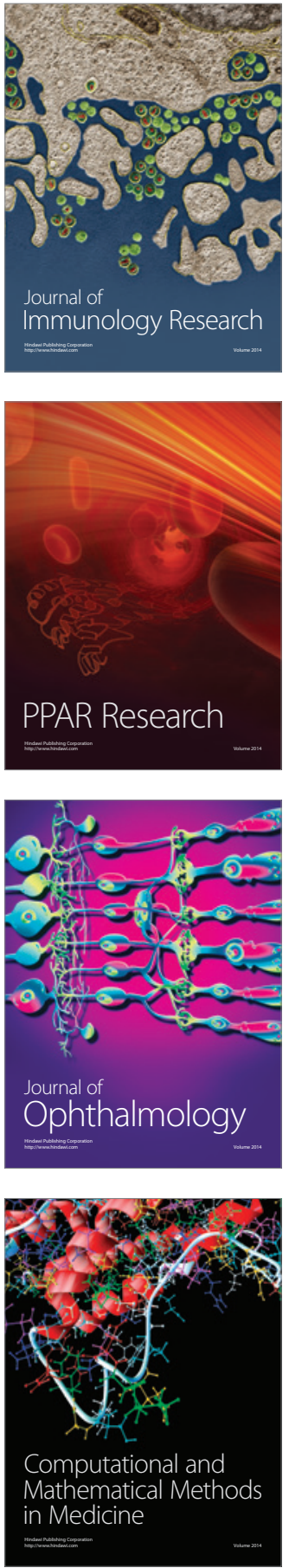

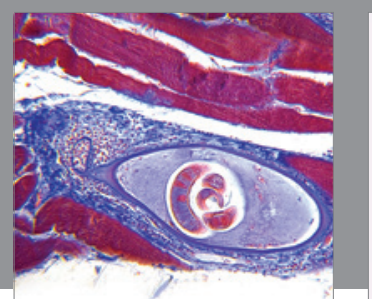

Gastroenterology Research and Practice

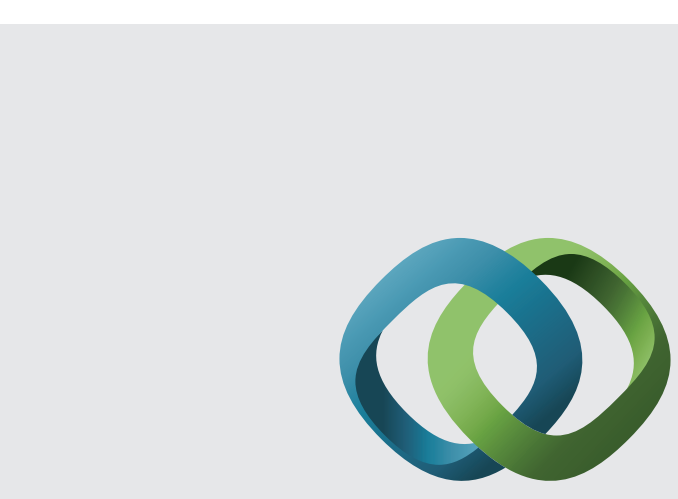

\section{Hindawi}

Submit your manuscripts at

http://www.hindawi.com
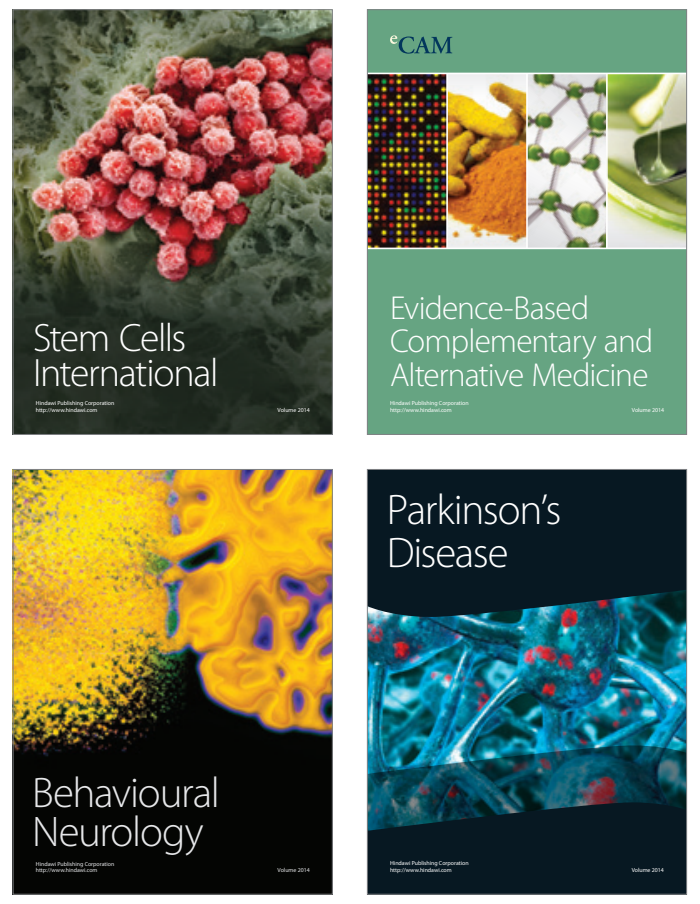
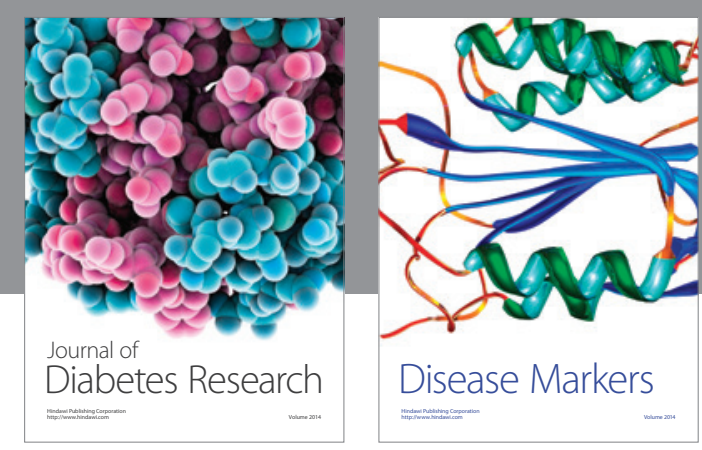

Disease Markers
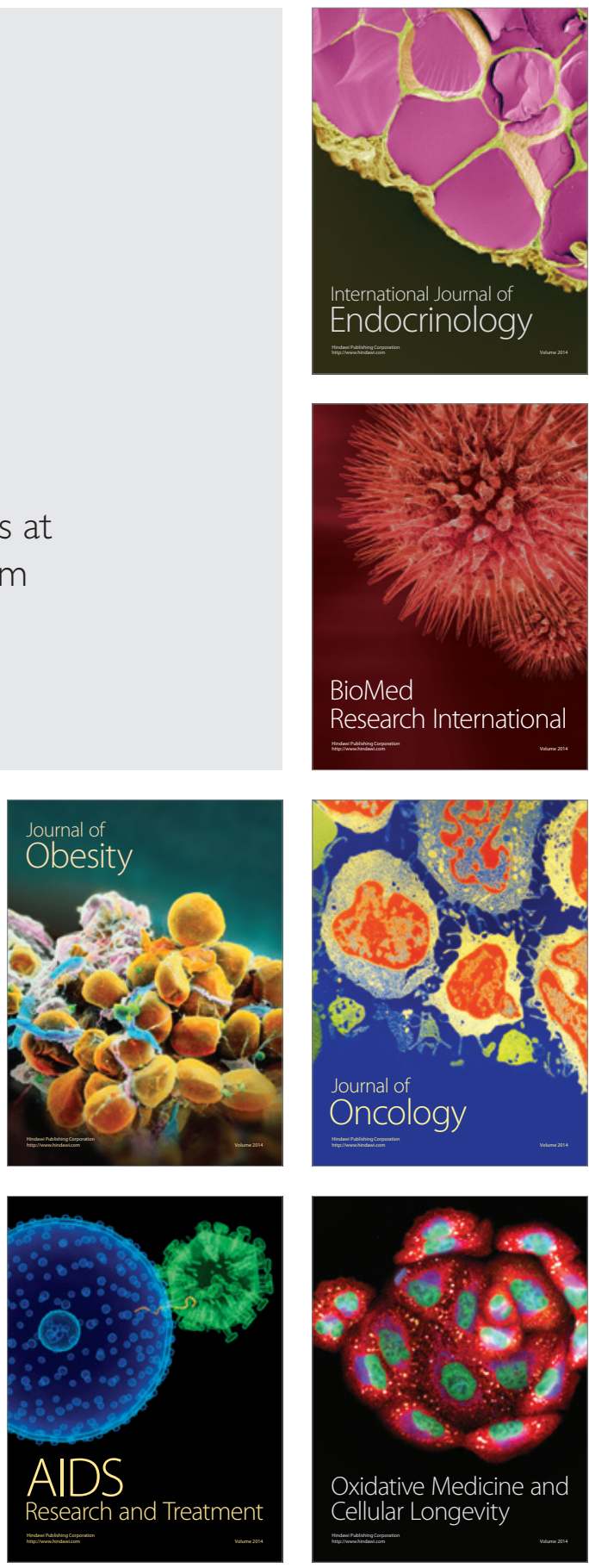